\title{
Hospitalization for epistaxis: a population-based healthcare research study in Thuringia, Germany
}

\author{
Max Kallenbach ${ }^{1} \cdot$ Andreas Dittberner $^{1} \cdot$ Daniel Boeger $^{2} \cdot$ Jens Buentzel ${ }^{3} \cdot$ Holger Kaftan $^{4} \cdot$ Kerstin Hoffmann $^{5}$. \\ Peter Jecker ${ }^{6} \cdot$ Andreas Mueller $^{7} \cdot$ Gerald Radtke $^{8} \cdot$ Orlando Guntinas-Lichius $^{1}{ }^{10}$
}

Received: 3 December 2019 / Accepted: 17 February 2020 / Published online: 2 March 2020

(c) The Author(s) 2020

\begin{abstract}
Purpose Epistaxis is the most common ENT emergency. The aim was to determine population-based data on severe epistaxis needing inpatient treatment.

Methods Retrospective population-based cohort study in the federal state Thuringia in 2016 performed on all 840 inpatients treated for epistaxis in otolaryngology departments (60.1\% male, median age: 73 years; $63.9 \%$ under anticoagulation). The association between patients' and treatment characteristics and longer inpatient stay ( $\geq 4$ days) as well as readmission for recurrent epistaxis was analyzed using univariable and multivariable statistics.

Results The overall incidence of epistaxis needing inpatient treatment was higher for men $(42$ per 100,000) than for women (28 per 100,000). The highest incidence was reached for men $>85$ years (222 per 100,000). Most important independent predictors for longer inpatient stay were localization of the bleeding not in the anterior nose $(\mathrm{OR}=2.045 ; \mathrm{CI}=1.534-2.726)$, recurrent bleeding during inpatient treatment $(\mathrm{OR}=2.142 ; \mathrm{CI}=1.508-3.042)$, no electrocoagulation $(\mathrm{OR}=2.810 ; \mathrm{CI}=2.047-$ $3.858)$, and blood transfusion $(\mathrm{OR}=2.731 ; \mathrm{CI}=1.324-5.635)$. Independent predictors for later readmission because of recurrent epistaxis were male gender $(\mathrm{OR}=1.756 ; \mathrm{CI}=1.155-2.668)$, oral anticoagulant use $(\mathrm{OR}=1.731 ; \mathrm{CI}=1.046-2.865)$, and hereditary hemorrhagic telangiectasia (OR =13.216; CI 5.102-34.231).

Conclusions Inpatient treatment of epistaxis seems to be variable in daily routine needing standardization by clinical guidelines and strategies to shorten inpatient treatment and to reduce the risk of readmission.
\end{abstract}

Keywords Bleeding $\cdot$ Epistaxis $\cdot$ Hospitalization $\cdot$ Diagnostics $\cdot$ Treatment $\cdot$ Nasal packing $\cdot$ Healthcare research $\cdot$ Anticoagulation

Electronic supplementary material The online version of this article (https://doi.org/10.1007/s00405-020-05875-2) contains supplementary material, which is available to authorized users.

Orlando Guntinas-Lichius

orlando.guntinas@med.uni-jena.de

1 Department of Otorhinolaryngology, Jena University Hospital, Am Klinikum 1, 07740 Jena, Germany

2 Department of Otorhinolaryngology, Zentralklinikum, Suhl, Germany

3 Department of Otorhinolaryngology, Südharz-Krankenhaus gGmbH, Nordhausen, Germany

4 Department of Otorhinolaryngology, Helios-Klinikum, Erfurt, Germany

\section{Introduction}

Epistaxis is a frequent emergency workload in ENT departments and many patients require an inpatient treatment [1-3]. As a result of the changing demographic structure, the number of older patients using classical anticoagulants

5 Department of Otorhinolaryngology, Sophien/Hufeland-Klinikum, Weimar, Germany

6 Department of Otorhinolaryngology, Klinikum Bad Salzungen, Bad Salzungen, Germany

7 Department of Otorhinolaryngology, SRH Wald-Klinikum, Gera, Germany

8 Department of Otorhinolaryngology, Ilm-Kreis-Kliniken, Arnstadt, Germany 
like Vitamin $\mathrm{K}$ antagonists (VKA) is increasing [4, 5]. Furthermore, new oral non-VKA oral anticoagulants (NOAC) are increasingly prescribed. The increased use of classical and new anticoagulants seems to increase the incidence of epistaxis [5]. The influence on more severe epistaxis and recurrent bleeding needing inpatient treatment is less clear $[3,5]$. The majority of data on epistaxis is based on hospital-based analyses. There is a lack of epidemiological, population-based data, especially for complicated recurrent epistaxis with readmission [3, 6-8]. Hence, not much is known about the burden for the general population, especially on the burden of severe epistaxis needing inpatient treatment.

Thuringia is a territorial state in Germany with approximately 2.2 Mio. inhabitants. There are only eight hospitals with departments of otolaryngology in Thuringia. The departments of otolaryngology have built a network primarily to improve health services research in the field of otolaryngology [9-13]. Use of this network provided an ideal platform for a population-based analysis of the inpatient treatment of epistaxis in daily practice in the year 2016 in Thuringia. The focus was on predictors for inpatient length of stay and for the risk of readmission because of recurrent epistaxis.

\section{Methods}

\section{Study design and patients}

The institutional ethics committee approved the study protocol for a retrospective data collection. A standardized retrospective analysis was performed in all eight Thuringian hospitals with a department of otolaryngology. All patients were selected who were coded for epistaxis (R04.0) due to the International Classification of Diseases [ICD], 10th revision, German modification; ICD-10-GM) and who were hospitalized for epistaxis in 2016 (index treatment). If a readmission for recurrent epistaxis occurred within 12 months, the readmission could occur in 2016 and for some cases also in 2017). A retrospective search of the patients' charts was performed, and the following variables were obtained: age, sex, medication, comorbidity, physical examinations, all diagnostics, medical treatment, and surgical procedures related to the epistaxis. Before analysis, the data were blinded with respected to the treating hospital. A systolic blood pressure value of $\geq 140 \mathrm{mmHg}$ and a diastolic value of $\geq 90 \mathrm{mmHg}$ defined as hypertension at admission. A systolic value of $\geq 180 \mathrm{mmHg}$ and/or a diastolic value of $\geq 120 \mathrm{mmHg}$ defined a hypertensive crisis. Anterior nose bleeding was defined as bleeding in the cartilaginous part of the septum (level of area I/II) including the Kiesselbach plexus. A bleeding posterior to the plexus was defined as posterior epistaxis.

The epidemiological calculations were based on the annual mean number of habitants in Thuringia in 2016. Population numbers were used that were given in the online database of the Thuringian State Office for Statistics (www. tls.thueringen.de).

\section{Statistical analysis}

If not indicated otherwise, data are presented with mean values \pm standard deviation (SD). All statistical analyses were performed using IBM SPSS, version 25. Parameter with $>10$ cases per item was included into further subanalysis. The Chi-square test was used to compare nominal data of two independent subgroups. The Mann-Whitney $U$-test was used to compare scaled data of two independent subgroups. Parameters from these univariable statistical tests with $p<0.1$ were included into multivariable binary logistic regression models with stepwise entry to analyse independent associations. Nominal $p$ values of two-tailed tests are reported. The significance level for the multivariable analyses was set at $p<0.05$.

\section{Results}

\section{Subjects, diagnostics, and treatment}

During the study period of 1 year, 840 patients $(60.1 \%$ male, median age: 73 years) were admitted for epistaxis in Thuringia. Table 1 shows the characteristics of the study cohort. The majority of the patients (63.9\%) used anti-platelet medications or anticoagulants (Vitamin K antagonist [VKA] and/ or Non-VKA oral anticoagulant [NOAC]). $12.9 \%$ had a double or triple anticoagulation. Arterial hypertension (57.7\%) was the most frequent comorbidity. Bleeding was localized in about half of the patients (54.9\%) in the anterior nose. The source of bleeding was not localized in $12.7 \%$. The number of cases was lowest in the summer time. The number of inpatient treatments in 2016 varied from 1 to 9 . The median duration of the inpatient treatment was 4 days. Supplement Table S1 summarizes the blood values and blood pressure measurements at admission. $20 \%$ of the patients had an international normalized ratio (INR) greater than 2.0, and $3.6 \%$ greater than 3.5. Half of the patients were hypertensive (49.6\%), and $12.7 \%$ had a hypertensive crisis. Table 2 gives an overview over the treatment. Nasal packing was the most frequent single measure used in $70.5 \%$ of the patients. Median nasal packing time was 1 day (range: 0-6). Electrocoagulation was used in $41.1 \%$ of the patients. Chemical etching, vessel ligation, or embolization were rarely used $(2.5 \%, 0.7 \%, 0.4 \%$ of the patients, respectively). Overall, 
Table 1 Characteristics of all patients with hospitalization because of epistaxis in 2016 $(N=840)$

\begin{tabular}{|c|c|c|}
\hline Parameter & $N$ & $\%$ \\
\hline \multicolumn{3}{|l|}{ Gender } \\
\hline Male & 505 & 60.1 \\
\hline Female & 335 & 39.9 \\
\hline \multicolumn{3}{|l|}{ Residence in Thuringia } \\
\hline Yes & 759 & 90.4 \\
\hline No & 81 & 9.6 \\
\hline \multicolumn{3}{|l|}{ Month of presentation } \\
\hline January & 88 & 10.5 \\
\hline February & 73 & 8.7 \\
\hline March & 102 & 12.1 \\
\hline April & 77 & 9.2 \\
\hline May & 78 & 9.3 \\
\hline June & 52 & 6.2 \\
\hline July & 62 & 7.4 \\
\hline August & 44 & 5.2 \\
\hline September & 47 & 5.6 \\
\hline October & 67 & 8.0 \\
\hline November & 67 & 8.0 \\
\hline December & 83 & 9.9 \\
\hline \multicolumn{3}{|l|}{ Weekend or holiday } \\
\hline Yes & 243 & 28.9 \\
\hline No & 597 & 71.1 \\
\hline \multicolumn{3}{|l|}{ Localization of the bleeding } \\
\hline Anterior & 461 & 54.9 \\
\hline Posterior & 166 & 19.8 \\
\hline Anterior and posterior & 9 & 1.1 \\
\hline Tumor* & 6 & 0.7 \\
\hline Not locatable & 107 & 12.7 \\
\hline Not documented & 91 & 10.8 \\
\hline \multicolumn{3}{|c|}{ Recurred episodes of active bleeding during same inpatient treatment } \\
\hline Yes & 184 & 21.9 \\
\hline No & 656 & 78.1 \\
\hline \multicolumn{3}{|c|}{ Patient under anticoagulation/blood thinner } \\
\hline Yes & 536 & 63.9 \\
\hline No & 304 & 36.2 \\
\hline \multicolumn{3}{|l|}{ Number of anticoagulant drugs } \\
\hline Single anticoagulation & 428 & 51.0 \\
\hline Double anticoagulation & 89 & 10.6 \\
\hline Triple anticoagulation & 19 & 2.3 \\
\hline No anticoagulation & 304 & 36.2 \\
\hline \multicolumn{3}{|l|}{ Type of anticoagulant/blood thinner } \\
\hline Anti-platelet drug & 280 & 33.3 \\
\hline Vitamin $\mathrm{K}$ antagonist (VKA) & 182 & 21.7 \\
\hline Non-VKA oral anticoagulant (NOAC) & 128 & 15.2 \\
\hline \multicolumn{3}{|l|}{ Comorbidity, epistaxis-relevant } \\
\hline Hypertension, arterial & 485 & 57.7 \\
\hline Diabetes mellitus & 193 & 22.9 \\
\hline Malignant tumor & 79 & 9.4 \\
\hline Coronary heart disease & 70 & 8.3 \\
\hline Anemia & 41 & 4.9 \\
\hline Hereditary hemorrhagic telangiectasia & 21 & 2.5 \\
\hline
\end{tabular}


Table 1 (continued)

\begin{tabular}{lll}
\hline Parameter & $N$ & $\%$ \\
\hline History of septoplasty & 10 & 1.2 \\
Alcohol abuse & 10 & 1.2 \\
Idiopathic thrombocytopenic purpura & 9 & 1.1 \\
Nasal septum perforation & 8 & 1.0 \\
History of FESS & 7 & 0.8 \\
Pregnancy & 5 & 0.6 \\
Factor V Leiden disease & 3 & 0.4 \\
Willebrand-Jürgens syndrome & 1 & 0.1 \\
Bernard-Soulier syndrome & 1 & 0.1 \\
Active bleeding at arrival & & \\
Yes & 612 & 72.9 \\
No & 228 & 27.1 \\
& Mean \pm SD & Median, range \\
Age, years & $66.6 \pm 20.9$ & $73,1-99$ \\
Duration of inpatient treatment, days & $4.2 \pm 3.2$ & $4.0,1-49$ \\
Number of inpatient treatments in 2016 & $1.2 \pm 0.6$ & $1,1-9$ \\
Number of outpatient/inpatient treatments in 2016 & $1.3 \pm 1.1$ & $1,1-20$ \\
Number of anticoagulants in patients under anticoagulation & $1.2 \pm 0.5$ & $1,1-3$ \\
\hline
\end{tabular}

*Tumor diagnosed later during inpatient work-up

FESS functional endoscopic sinus surgery, $S D$ standard deviation

$41.8 \%$ needed surgery and in $17.4 \%$ in general anesthesia. Anticoagulant medication was stopped in $21 \%$ of the anticoagulant users. Furthermore, $17.5 \%$ needed a substitution of the anticoagulant (in most cases by enoxaparin).

\section{Incidence of inpatient treatment for epistaxis}

Overall, the incidence for the need of an inpatient treatment for the patients living in Thuringia $(90.8 \%$ of the study population) was 35 per 100,000 persons (Supplement Table 2). The incidence was higher for men (42 per 100,000) than for women (28 per 100,000). This gender difference became particularly evident for patients older than 70 years of age (Fig. 1). The incidence continuously increased for both sexes for patients older than 45 years with a steep increase for patients above 70 years. The highest incidence was reached for men older than 85 years with an incidence of 222 per 100,000 persons.

\section{Predictors for the duration of the inpatient treatment}

Half of the patients $(50.6 \%)$ had an inpatient length of stay of $\geq 4$ days. Supplement Table 3 gives a summary over the univariate analyses on predictors for a longer length of inpatient stay ( $\geq 4$ days). Anti-platelet drug use, anticoagulant combination therapy with 2-3 drugs, need for pause of the anticoagulant therapy, arterial hypertension, diabetes mellitus, localization of the bleeding not in the anterior nose, recurrent bleeding during the inpatient stay, need for nose packing, no electrocoagulation, and need for blood transfusion were univariate predictors for a longer inpatient stay (all $p<0.1$ ). The multivariate analyses with these factors revealed several independent predictors for longer inpatient treatment (Table 3). The following patients' characteristics were independent predictors (all $p<0.05$ ): anti-platelet drug (Odds ratio $[\mathrm{OR}]=1.825 ; 95 \%$ confidence interval $[\mathrm{CI}]=1.221-2.729)$, need for pause of anticoagulation therapy $(\mathrm{OR}=1.856 ; \mathrm{CI}=1.295-2.659)$, arterial hypertension $(\mathrm{OR}=1.415 ; \mathrm{CI}=1.052-1.902)$, diabetes mellitus $(\mathrm{OR}=1.489 ; \mathrm{CI}=1.050-2.113)$, localization of the bleeding not in the anterior nose $(\mathrm{OR}=2.045 ; \mathrm{CI}=1.534-2.726)$, and recurrent bleeding during inpatient treatment $(\mathrm{OR}=2.142$; $\mathrm{CI}=1.508-3.042)$. Furthermore, the following treatment factors were predictive: nose packing $(\mathrm{OR}=2.568$; $\mathrm{CI}=1.822-3.619)$, no electrocoagulation $(\mathrm{OR}=2.810$; $\mathrm{CI}=2.047-3.858)$, and blood transfusion $(\mathrm{OR}=2.731$; $\mathrm{CI}=1.324-5.635)$.

\section{Predictors for readmission for recurrent epistaxis}

One hundred and thirty-four (134) patients (16.0\%) were readmitted within 12 months for recurrent epistaxis. The results of the univariate analyses on predictors for readmission because of recurrent epistaxis are listed in Supplement Table 4. Male gender, use of non-vitamin $\mathrm{K}$ antagonist (VKA) oral anticoagulants (NOAC), use of 2-3 anticoagulants, length of index admission $\geq 4$ days, hereditary 
Table 2 Overview about the used therapeutic methods

\begin{tabular}{|c|c|c|}
\hline Parameter & $N$ & $\%$ \\
\hline \multicolumn{3}{|l|}{ Cold package } \\
\hline Yes & 214 & 25.5 \\
\hline No & 626 & 75.7 \\
\hline \multicolumn{3}{|l|}{ Nasal packing } \\
\hline Yes & 592 & 70.5 \\
\hline No & 248 & 29.5 \\
\hline \multicolumn{3}{|l|}{ Pause anticoagulant } \\
\hline Yes & 117 & 13.9 \\
\hline No & 419 & 49.8 \\
\hline No anticoagulant treatment & 304 & 36.2 \\
\hline \multicolumn{3}{|c|}{ Substitution of the anticoagulant } \\
\hline Yes & 94 & 11.2 \\
\hline No & 442 & 52.6 \\
\hline No anticoagulant treatment & 304 & 36.2 \\
\hline \multicolumn{3}{|l|}{ Any kind of surgery } \\
\hline Yes & 505 & 60.1 \\
\hline No & 335 & 39.9 \\
\hline \multicolumn{3}{|l|}{ Anesthesia } \\
\hline No & 449 & 53.5 \\
\hline Local & 245 & 29.2 \\
\hline General & 146 & 17.4 \\
\hline \multicolumn{3}{|l|}{ Electrocoagulation } \\
\hline Yes & 345 & 41.1 \\
\hline No & 495 & 58.9 \\
\hline \multicolumn{3}{|c|}{ Cauterization with silver nitrate or trichloroacetic acid } \\
\hline Yes & 21 & 2.5 \\
\hline No & 819 & 97.5 \\
\hline \multicolumn{3}{|l|}{ Embolization } \\
\hline Yes & 3 & 0.4 \\
\hline No & 837 & 99.6 \\
\hline \multicolumn{3}{|l|}{ Vessel ligation } \\
\hline Yes & 6 & 0.7 \\
\hline No & 834 & 99.3 \\
\hline \multicolumn{3}{|l|}{ Further analgesia } \\
\hline Yes & 118 & 14.0 \\
\hline No & 722 & 86.0 \\
\hline \multicolumn{3}{|l|}{ Nasal oil, ointment } \\
\hline Yes & 691 & 82.3 \\
\hline No & 149 & 17.7 \\
\hline \multicolumn{3}{|l|}{ Antibiotics } \\
\hline Yes & 238 & 28.3 \\
\hline No & 602 & 71.7 \\
\hline \multicolumn{3}{|l|}{ Antihypertensive drugs } \\
\hline Yes & 101 & 12.0 \\
\hline No & 739 & 88.0 \\
\hline \multicolumn{3}{|l|}{ Fluid replacement } \\
\hline Yes & 130 & 15.5 \\
\hline No & 710 & 84.5 \\
\hline \multicolumn{3}{|l|}{ Blood transfusion } \\
\hline Yes & 40 & 4.8 \\
\hline
\end{tabular}

Table 2 (continued)

\begin{tabular}{lll}
\hline Parameter & $N$ & $\%$ \\
\hline No & 800 & 95.2 \\
Iron & & \\
Yes & 23 & 2.7 \\
No & 817 & 97.3 \\
Vitamin $K$ & & \\
Yes & 27 & 3.2 \\
No & 813 & 96.8 \\
Coagulation factor substitution & & \\
Yes & 5 & 0.6 \\
No & 835 & 99.4 \\
Thrombocyte substitution & & \\
Yes & 2 & 0.2 \\
No & 838 & 99.8 \\
Transferal to intensive care unit & & \\
Yes & 21 & 2.5 \\
No & 819 & 97.5 \\
& Mean \pm SD & Median, range \\
Number of surgeries per patient & $0.6 \pm 0.6$ & $1.0,0-5$ \\
Number of drug treatments per patient & $1.9 \pm 1.1$ & $2.0,0-6$ \\
Nasal packings per patient & $1.1 \pm 0.9$ & $1.0,0-7$ \\
Duration of nasal packing, days & $1.1 \pm 1.0$ & $1.0,0-6$ \\
\hline SN & &
\end{tabular}

$S D$ standard deviation

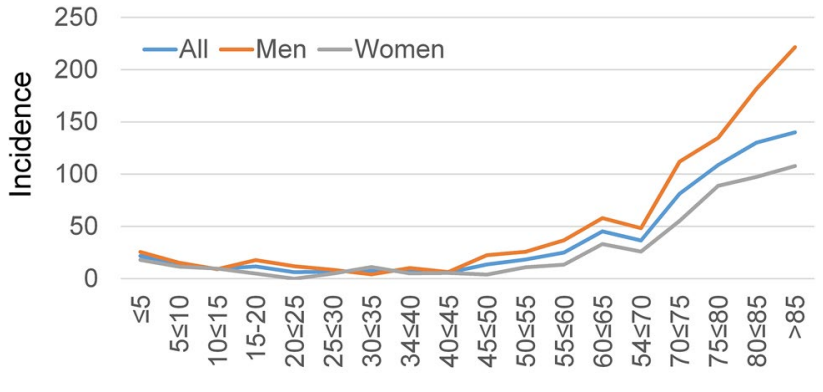

Age in years

Fig. 1 Incidence (N/100.000 population) of inpatient epistaxis treatment for the different age cohorts in Thuringia in 2016 of the patients living in Thuringia ( $N=763 ; 90.8 \%$ of the study population)

hemorrhagic telangiectasia, recurrent bleeding during inpatient treatment, and nose packing were univariate predictors for readmission (all $p<0.1$ ). The multivariate analyses with these factors revealed several independent predictors (all $p<0.05$ ) for later readmission (Table 4). The following patients' characteristics were independent predictors: male gender $(\mathrm{OR}=1.756 ; \mathrm{CI}=1.155-2.668)$, NOAC use $(\mathrm{OR}=1.731 ; \mathrm{CI}=1.046-2.865)$, hereditary hemorrhagic telangiectasia $(\mathrm{OR}=13.216$; $\mathrm{CI} 5.102-34.231)$, and recurrent bleeding during index inpatient treatment $(\mathrm{OR}=1.790$; $\mathrm{CI}=1.167-2.745$ ). 
Table 3 Independent associations between patients' characteristics, treatment, and the probability to have a shorter (1-3 days; reference) or longer ( $\geq 4$ days) days of inpatient treatment

\begin{tabular}{|c|c|c|c|c|c|}
\hline Measure & & $\mathrm{OR}^{*}$ & $95 \% \mathrm{CI}^{*}$ lower & $95 \% \mathrm{CI}^{*}$ upper & $p$ \\
\hline \multicolumn{6}{|c|}{ Model 1: patients' characteristics } \\
\hline \multirow[t]{2}{*}{ Anti-platelet drug } & No & 1 & & & \\
\hline & Yes & 1.825 & 1.221 & 2.729 & 0.003 \\
\hline \multirow{2}{*}{$\begin{array}{l}\text { Anticoagulant combination } \\
\text { therapy, number of drugs }\end{array}$} & 0 or 1 drug & 1 & & & \\
\hline & 2 or 3 drugs & 1.223 & 0.659 & 2.268 & 0.523 \\
\hline \multirow[t]{2}{*}{ Pause of anticoagulation } & No & 1 & & & \\
\hline & Yes & 1.856 & 1.295 & 2.659 & 0.001 \\
\hline \multirow[t]{2}{*}{ Hypertension, arterial } & No & 1 & & & \\
\hline & Yes & 1.415 & 1.052 & 1.902 & 0.022 \\
\hline \multirow[t]{2}{*}{ Diabetes mellitus } & No & 1 & & & \\
\hline & Yes & 1.489 & 1.050 & 2.113 & 0.026 \\
\hline \multirow[t]{2}{*}{ Localization of the bleeding } & Anterior & 1 & & & \\
\hline & Not anterior & 2.045 & 1.534 & 2.726 & $<0.001$ \\
\hline \multirow{2}{*}{$\begin{array}{l}\text { Recurrent bleeding during } \\
\text { inpatient treatment }\end{array}$} & No & 1 & & & \\
\hline & Yes & 2.142 & 1.508 & 3.042 & $<0.001$ \\
\hline \multicolumn{6}{|l|}{ Model 2: treatment } \\
\hline \multirow[t]{2}{*}{ Nose packing } & No & 1 & & & \\
\hline & Yes & 2.568 & 1.822 & 3.619 & $<0.001$ \\
\hline \multirow[t]{2}{*}{ Electrocoagulation } & Yes & 1 & & & \\
\hline & No & 2.810 & 2.047 & 3.858 & $<0.001$ \\
\hline \multirow[t]{2}{*}{ Blood transfusion } & No & 1 & & & \\
\hline & Yes & 2.731 & 1.324 & 5.635 & 0.007 \\
\hline
\end{tabular}

Multivariable binary logistic regression for the dichotomized outcome parameter length of inpatient stay: OR related to a shorter length of stay. Significant $p$ values $(p<0.05)$ in bold

$O R$ odds ratio, $C I$ confidence interval

Table 4 Independent associations between patients' characteristics, treatment, and the probability to be readmitted for recurrent epistaxis (patients without versus with readmission for recurrent epistaxis)

\begin{tabular}{|c|c|c|c|c|c|}
\hline Measure & & $\mathrm{OR}^{*}$ & $95 \%$ CI* lower & $95 \% \mathrm{CI}^{*}$ upper & $p$ \\
\hline \multicolumn{6}{|l|}{ Model 1: patients' characteristics } \\
\hline \multirow[t]{2}{*}{ Gender } & Female & 1 & & & \\
\hline & Male & 1.756 & 1.155 & 2.668 & 0.008 \\
\hline \multirow[t]{2}{*}{ Non-VKA oral anticoagulant (NOAC) } & No & 1 & & & \\
\hline & Yes & 1.731 & 1.046 & 2.865 & $\mathbf{0 . 0 3 3}$ \\
\hline \multirow[t]{2}{*}{ Anticoagulant combination therapy } & 0 or 1 drug & 1 & & & \\
\hline & 2 or 3 drugs & 1.484 & 0.767 & 2.870 & 0.241 \\
\hline \multirow[t]{2}{*}{ Length of stay } & 1-3 days & 1 & & & \\
\hline & $\geq 4$ days & 1.272 & 0.858 & 1.886 & 0.230 \\
\hline \multirow[t]{2}{*}{ Hereditary hemorrhagic telangiectasia } & No & 1 & & & \\
\hline & Yes & 13.216 & 5.102 & 34.231 & $<0.001$ \\
\hline \multirow[t]{2}{*}{ Recurrent bleeding during inpatient treatment } & No & 1 & & & \\
\hline & Yes & 1.790 & 1.167 & 2.745 & 0.008 \\
\hline \multicolumn{6}{|l|}{ Model 2: treatment } \\
\hline \multirow[t]{2}{*}{ Nose packing } & No & & & & \\
\hline & Yes & 1.469 & 0.996 & 2.165 & 0.052 \\
\hline
\end{tabular}

Multivariable binary logistic regression for the dichotomized outcome parameter readmission for recurrent epistaxis with OR related to no readmission. Significant $p$ values $(p<0.05)$ in bold

$O R$ odds ratio, $C I$ confidence interval 


\section{Discussion}

The presented population-based study on an actual and complete year of inpatient treatment for severe epistaxis in a territorial federal state in Germany revealed that the affected population was mainly elderly and comorbid persons with male predominance. The incidence was strongly increases beyond 70 years of age. Beyond nasal packing, treatment decisions were variable. Half of the patients needed a length of stay of $\geq 4$ days. Anti-platelet drug use, need to pause of anticoagulation therapy, localization of the bleeding not in the anterior region, recurrent bleeding during inpatient treatment were patient factors leading to longer inpatient length of stay. The stay was also longer if electrocoagulation is not possible to stop the nose bleeding, or use of blood transfusion. Male gender, oral anticoagulant use, hereditary hemorrhagic telangiectasia, and recurrent bleeding during index inpatient treatment were important risk factors for later readmission because of recurrent epistaxis. Decision making for inpatient treatment of epistaxis should be standardized by the use of clinical guidelines to implement strategies to shorten inpatient treatment and to reduce the risk of readmission.

There are only a few actual population-based studies on inpatient treatment of epistaxis [2, 3, 6, 14]. Furthermore, there is only one other population-based study on factors influencing readmission for recurrent epistaxis [8]. A strength of the present study is the combination of population-based data (all epistaxis inpatients of one federal state in one year) with hospital-based data as the hospital charts of all 840 patients were additionally analyzed. Therefore, detailed data on patients' characteristics, diagnostic results, and treatment in daily practice beyond clinical trials could be investigated.

The retrospective design is a limitation of the study. A selection bias cannot be ruled out as the criteria to admit the patients for inpatient treatment remain unclear. Furthermore, several important parameters could not be assessed. Epistaxis is an important mortality factor but mortality could not be estimated [3, 15]. A low socioeconomic status and deprivation have been shown as reason for admission, too, but could not be investigated [3].

The incidence of ENT/emergency department visits was estimated with $108 / 100,000$ population per year for the United Kingdom and with about 170/100,000 (1200/100,000 for patients aged 70-79 years) for the United States in the last decade [2,6]. About $5 \%$ of these patients required admission [6]. The admission policies might be different, but compared to these studies, the number of patients needing admission for epistaxis was much higher in Thuringia a century later. This trend can be seen all over Germany [16]. The strong increase of incidence in elderly people that was seen already a century ago might have risen further [2].

Others have also shown a male predominance, cardiovascular disease as frequent comorbidity, and overpresentation of patients with anti-platelet drug and anticoagulant use $[3,5,7,8,17,18]$. Data on duration of admission are sparse. The main duration of inpatient treatment in Wales from 1995 to 2009 was 3.2 days [7]. We could not identify any other study analyzing risk factors for a longer duration of stay. Epistaxis patients have a high risk of about 14-20\% of readmission with recurrent epistaxis $[8,19]$. This could be confirmed by the present study. Recently, Chaaban et al. revealed by multivariate analysis that age $>75$ years, male gender, anterior packing/cautery, congestive heart failure, diabetes mellitus, and obstructive sleep apnea were independent predictors for readmission in a series of 4120 patients (5\% of the United States sample of Medicare data from 2012 to 2013) [8]. Cohen et al. further differentiated between early (within 30 days) and late readmission [19]. Based on multivariate analysis in a case series of 653 patients treated in a single Israeli academic center, prior nasal surgery and anemia were independent risk factors for early readmission.

First, it would be helpful to establish a standardized clinical guideline for epistaxis management at index presentation, decision making for inpatient treatment, and standardized inpatient treatment. This might help to reduce admission rates and length of hospital stay [20]. Of course, nasal packing might be the only first choice of treatment in severe epistaxis, but it leads to longer hospital stay and is a risk factor for readmission [21]. Especially for anterior epistaxis, identification of the bleeding source and treatment by electrocautery or chemical cautery increases the success rate and reduces the risk of recurrent bleeding [21]. Therefore, early removal of the nasal packing in such patients (after initial stabilization, blood pressure regulation, and stop of anticoagulants) might be worthwhile to repeat a careful endoscopy of the nose, identify and coagulate the bleeding source. In patients with continuous posterior bleeding, early indication for endoscopic sphenopalatine artery cauterization might also help to reduce the risk of recurrent bleeding [22].

\section{Conclusions}

Male gender, oral anticoagulant use, hereditary hemorrhagic telangiectasia, and recurrent bleeding during index inpatient treatment were the important risk factors for readmission. A strategy to be analyzed in further studies might be (a) to arrange controls at the general physician in regard of, for instance, anticoagulant use, blood pressure control, or nasal mucosa care in patients with hereditary hemorrhagic 
telangiectasia, or (b) to schedule strict follow-up visits for these patients at risk to see if this strategy helps to reduce the risk for recurrent nose bleeding.

Acknowledgement Open Access funding provided by Projekt DEAL. Orlando Guntinas-Lichius wrote the first draft of the manuscript. No honorarium, grant, or other form of payment was given to anyone to produce the manuscript. Each author listed on the manuscript has seen and approved the submission of this version of the manuscript and takes full responsibility for the manuscript

Funding The authors received no specific funding for this work.

\section{Compliance with ethical standards}

Conflict of interest The authors have declared that no competing interests exist.

Open Access This article is licensed under a Creative Commons Attribution 4.0 International License, which permits use, sharing, adaptation, distribution and reproduction in any medium or format, as long as you give appropriate credit to the original author(s) and the source, provide a link to the Creative Commons licence, and indicate if changes were made. The images or other third party material in this article are included in the article's Creative Commons licence, unless indicated otherwise in a credit line to the material. If material is not included in the article's Creative Commons licence and your intended use is not permitted by statutory regulation or exceeds the permitted use, you will need to obtain permission directly from the copyright holder. To view a copy of this licence, visit http://creativecommons.org/licenses/by/4.0/.

\section{References}

1. Stell PM (1977) Epistaxis. Clin Otolaryngol Allied Sci 1977(2):263-273

2. Walker TW, Macfarlane TV, McGarry GW (2007) The epidemiology and chronobiology of epistaxis: an investigation of Scottish hospital admissions 1995-2004. Clin Otolarynol 32:361-365

3. Douglas CM, Tikka T, Broadbent B, Calder N, Montgomery J (2007) Patterns of hospital admission in 54501 patients with epistaxis over a 20-year period in Scotland. UK Clin Otolarynol 43:1465-1470

4. Rubboli A, Becattini C, Verheugt FW (2011) Incidence, clinical impact and risk of bleeding during oral anticoagulation therapy. World J Cardiol 3:351-358

5. Buchberger AMS, Baumann A, Johnson F et al (2018) The role of oral anticoagulants in epistaxis. Eur Arch Otorhinolaryngol 275:2035-2043

6. Pallin DJ, Chang YM, McKay MP, Emond JA, Pelletier AJ, Camargo CA Jr (2005) Epidemiology of epistaxis in US emergency departments, 1992 to 2001. Ann Emerg Med 46:77-81

7. Fishpool SJ, Tomkinson A (2012) Patterns of hospital admission with epistaxis for 26,725 patients over an 18-year period in Wales UK. Ann R Coll Surg Eng1 94:559-562
8. Chaaban MR, Zhang D, Resto V, Goodwin JS (2018) Factors influencing recurrent emergency department visits for epistaxis in the elderly. Auris Nasus Larynx 45:760-764

9. Moeller K, Esser D, Boeger D et al (2013) Parotidectomy and submandibulectomy for benign diseases in Thuringia, Germany: a population-based study on epidemiology and outcome. Eur Arch Otorhinolaryngol 270:1149-1155

10. Fiedler T, Boeger D, Buentzel J et al (2013) Middle ear surgery in Thuringia, Germany: a population-based regional study on epidemiology and outcome. Otol Neurotol 34:890-897

11. Mueller J, Boeger D, Buentzel J et al (2015) Population-based analysis of tonsil surgery and postoperative hemorrhage. Eur Arch Otorhinolaryngol 272:3769-3777

12. Plumbaum K, Volk GF, Boeger D et al (2017) Inpatient treatment of patients with acute idiopathic peripheral facial palsy: a population-based healthcare research study. Clin Otolarynol 42:1267-1274

13. Renner V, Geissler K, Boeger D et al (2017) Inpatient treatment of patients admitted for dizziness: a population-based healthcare research study on epidemiology, diagnosis, treatment, and outcome. Otol Neurotol 38:e460-e469

14. Villwock JA, Jones K (2013) Recent trends in epistaxis management in the United States: 2008-2010. JAMA Otolaryngol Head Neck Surg 139:1279-1284

15. Corr MJ, Tikka T, Douglas CM, Marshall J (2019) One-year allcause mortality for 338 patients admitted with epistaxis in a large tertiary ENT centre. J Laryngol Otol 133:487-493

16. Bermuller C, Bender M, Brogger C, Petereit F, Schulz M (2014) Epistaxis and anticoagulation - a medical and economic challenge? Laryngorhinootol 93:249-255

17. Kunz SM, Holzmann D, Soyka MB (2019) Association of epistaxis with atherosclerotic cardiovascular disease. Laryngoscope 129:783-787

18. Marin E, Watelet JB, Gevaert P, Van Zele T (2019) Severe spontaneous epistaxis: retrospective study in a tertiary ENT centre. Eur Arch Otorhinolaryngol. 276:1693-1699

19. Cohen O, Shoffel-Havakuk H, Warman M et al (2017) Early and late recurrent epistaxis admissions: patterns of incidence and risk factors. Otolaryngol Head Neck Surg 157:424-431

20. Javed F, Foxton C, Daudia A (2012) The application of modified guidelines for epistaxis management: our experience in 30 patients before and 32 patients after audit. Clin Otolarynol 37:151-155

21. Shargorodsky J, Bleier BS, Holbrook EH et al (2013) Outcomes analysis in epistaxis management: development of a therapeutic algorithm. Otolaryngol Head Neck Surg 149:390-398

22. Moshaver A, Harris JR, Liu R, Diamond C, Seikaly H (2004) Early operative intervention versus conventional treatment in epistaxis: randomized prospective trial. J Laryngol Otol $33: 185-188$

Publisher's Note Springer Nature remains neutral with regard to jurisdictional claims in published maps and institutional affiliations. 